to see around and to participate in the floating crap game in back of the cigar store on 44th. Or, alternatively, in the Biltmore Garage if, as seems likely, the back of the Police Station continues to be out. All this friendly nattering does me a lot of good and I can feel that my blood pressure is already creeping down to normal. We say a cordial farewell and on the way home I tell cousin Norman that in my opinion old Doc Teacher is very up and coming in the National Health Racket and is set to be, provided he avoids bad company and pays his dues, the most respected croaker in town.

We are grateful to John Salinsky for these extracts from Norman Gland's diary.

DOI: 10.3399/bjgp08X302871

\title{
Launch of the Association for Young People's Health
}

Growing concerns about the health of young people continue. The UNICEF report in 2007 placed Britain at the bottom of the 21 richest countries in terms of how children and young people rated their emotional wellbeing. ${ }^{1}$ UK teenagers undertake more risky behaviour than any other European nations' youth, increasing the harm associated with unprotected sex, smoking, alcohol and substance abuse along with unhealthy eating habits. Some improvements have been made. We now have the lowest rate of underage conception for 20 years, ${ }^{2}$ which is clearly good news. However, one interpretation of the statistics ${ }^{2}$ still estimates a current rate of 1 in 50 UK schoolgirls falling pregnant which seems like poor progress in an era of increased focus on sexual health, informed by pivotal documents such as the NSF Framework for Children, Young people and Maternity Services (2004) and the RCGP initiative Getting it Right for Teenagers in Your Practice. ${ }^{3}$ Obesity is also on the rise and will continue to compromise the health of young people for years to come.

There is no doubt that the statistics for young people's health are worrying but they are not being ignored. February 2008 saw the launch of a new multidisciplinary organisation The Association for Young People's Health (AYPH) with an inaugural meeting held at The Institute of Child Health. The aims of the AYPH are multi fold and include advocacy, dissemination of information, and affiliation with international bodies concerned with the health of young people. The organisation acknowledges the importance of supporting and promoting research in this area and its multidisciplinary base will facilitate translational research. The RCGP Adolescent Task Group has been a key driver behind the development of the organisation and under the leadership of Dr Dick Churchill has been a major player in the production of training materials in adolescent health. The Adolescent Health Project is an e-learning initiative aimed at providing training for post-registration health professionals from a range of disciplines and seeks to address the gap in training opportunities that currently exists.

No one denies that working with teenagers is challenging but the marginalisation of their needs and the lamentable state of health that many endure, notably in terms of poor emotional and mental health with only $25 \%$ of mental disorders detected in community samples, ${ }^{4}$ behoves us to be more proactive. This is where the AYPH seeks to raise the profile, increase our knowledge base and be an important advocate. Membership is currently free for this first year - please log onto http://www.youngpeopleshealth.org.uk.

\section{Jane H Roberts}

\section{REFERENCES}

1. UNICEF. Child poverty in perspective: An overview of child well-being in rich countries. Florence, Italy: The United Nations Children's Fund, 2007.

http://www.unicef-icdc.org/presscentre/presskit/ reportcard7/rc7_eng.pdf (accessed 12 May 2008).

2. Office of National Statistics and Teenage Pregnancy Unit, 2008. Teenage pregnancy. London: Department for Children, Schools and Families, 1995.

http://www.everychildmatters.gov.uk/teenagepregnan cy/ (accessed 12 May 2008)

3. Royal College of General Practitioners and Royal College of Nursing. Getting it Right for Teenagers in your Practice. London: RCGP \& RCN, Department of Health, 2002.

4. National Institute for Clinical Excellence. Depression in children and young people. London: NICE, 2005.

DOI: 10.3399/bjgp08X302880 